\title{
ROS-talk - how the apoplast, the chloroplast, and the nucleus get the message through
}

\author{
Alexey Shapiguzov, Julia P. Vainonen, Michael Wrzaczek and Jaakko Kangasjärvi*
}

Division of Plant Biology, Department of Biosciences, University of Helsinki, Helsinki, Finland

Edited by:

Dario Leister, Ludwig Maximilian

University of Munich, Germany

\section{Reviewed by:}

Daniel Hofius, Swedish University of Agricultural Sciences, Sweden

Markus Wirtz, Centre for Organismal Studies, Germany

Veronica G. Maurino, Heinrich-HeineUniversity Düsseldorf, Germany

\section{*Correspondence:}

Jaakko Kangasjärvi, Division of Plant Biology, Department of Biosciences, University of Helsinki, Viikinkaari 1, P.O. Box 65, FIN-00014 Helsinki, Finland.

e-mail: jaakko.kangasjarvi@helsinki.fi
The production of reactive oxygen species (ROS) in different plant subcellular compartments is the hallmark of the response to many stress stimuli and developmental cues. The past two decades have seen a transition from regarding ROS as exclusively cytotoxic agents to being considered as reactive compounds which participate in elaborate signaling networks connecting various aspects of plant life. We have now arrived at a stage where it has become increasingly difficult to disregard the communication between different types and pools of ROS. Production of ROS in the extracellular space, the apoplast, can influence their generation in the chloroplast and both can regulate nuclear gene expression. In spite of existing information on these signaling events, we can still barely grasp the mechanisms of ROS signaling and communication between the organelles. In this review, we summarize evidence that supports the mutual influence of extracellular and chloroplastic ROS production on nuclear gene regulation and how this interaction might occur. We also reflect on how, and via which routes signals might reach the nucleus where they are ultimately integrated for transcriptional reprogramming. New ideas and approaches will be needed in the future to address the pressing questions of how ROS as signaling molecules can participate in the coordination of stress adaptation and development and how they are involved in the chatter of the organelles.

Keywords: ROS signaling, apoplast, chloroplasts, retrograde signaling, Arabidopsis thaliana

\section{INTRODUCTION}

During their life plants face a vast set of environmental challenges: extreme changes in ambient illumination, temperature, and humidity, differences in soil salinity, attack by pathogens and herbivores, mechanical wounding, etc. To withstand all these challenges, plants have developed a repertoire of signaling pathways that is unparalleled in its complexity among living organisms. Signaling through plant hormones (Vanstraelen and Benková, 2012), cell surface receptors (Geldner and Robatzek, 2008), and light perception by plastids and photoreceptors (Kami et al., 2010) are integrated in the cell to eventually reprogram gene expression and metabolism and shape strategic decisions on plant stress response and development (Jaillais and Chory, 2010).

A critical role in this signal integration and decision-making is played by a class of reactive forms of the molecular oxygen, collectively referred to as reactive oxygen species (ROS; Murphy et al., 2011; Kangasjärvi et al., 2012). ROS, including singlet oxygen $\left({ }^{1} \mathrm{O}_{2}\right)$, superoxide $\left(\mathrm{O}_{2}^{\bullet-}\right)$, hydrogen peroxide $\left(\mathrm{H}_{2} \mathrm{O}_{2}\right)$, and hydroxyl radical $(\bullet \mathrm{OH})$ are unavoidable by-products of aerobic metabolism (Imlay, 2003, 2008; Ogilby, 2010) which have traditionally been regarded mainly as damaging cytotoxic agents. In line with this view, life has developed a plethora of ROS scavenging systems including the low-molecular weight compounds ascorbic acid and glutathione (Foyer and Noctor, 2011) as well as different classes of antioxidant enzymes (Apel and Hirt, 2004). During the recent years, however, a new concept has emerged where ROS play important signaling roles during development and stress responses, and controlled production of ROS acts as a signal. ROS are generated in many compartments of plant cells. Whereas the "ROS landscape" of the animal cell is dominated by mitochondria as the main source of ROS (Marchi et al., 2012), the role of these organelles in ROS production in plants is more subtle (Dutilleul et al., 2003; Suzuki et al., 2012) and is not addressed in this review. Apart from mitochondria, ROS are produced in the chloroplasts, the peroxisomes, and the apoplast, as well as in less commonly known locations, the nucleus and the endoplasmic reticulum (Overmyer et al., 2003; Ashtamker et al., 2007; Foyer and Noctor, 2009; Jaspers and Kangasjärvi, 2010; Mazars et al., 2010). Yet uncharacterized signaling networks between the organelles that employ ROS as second messengers have recently raised considerable interest (Figure 1). For example, ROS that are produced in the chloroplast have been implicated as intermediates in retrograde signaling from chloroplast to nucleus during acclimation of photosynthesis (Nott et al., 2006; Galvez-Valdivieso and Mullineaux, 2010). Intriguingly, however, it has recently been realized that the role of this signaling goes beyond optimization of photosynthesis: chloroplastic ROS production and photosynthetic functions are also regulated by cues that are perceived in the cell wall, frequently referred to as the extracellular space or the apoplast (Padmanabhan and Dinesh-Kumar, 2010). Thus, the sensu stricto retrograde signaling (from chloroplast to nucleus) can also be regarded as a part of a larger network where apoplastic signals induce the generation of ROS in the chloroplast, which in turn leads to regulation of nuclear gene expression by several still uncharacterized, but at least partially chloroplast-derived, ROS-dependent retrograde signals. 


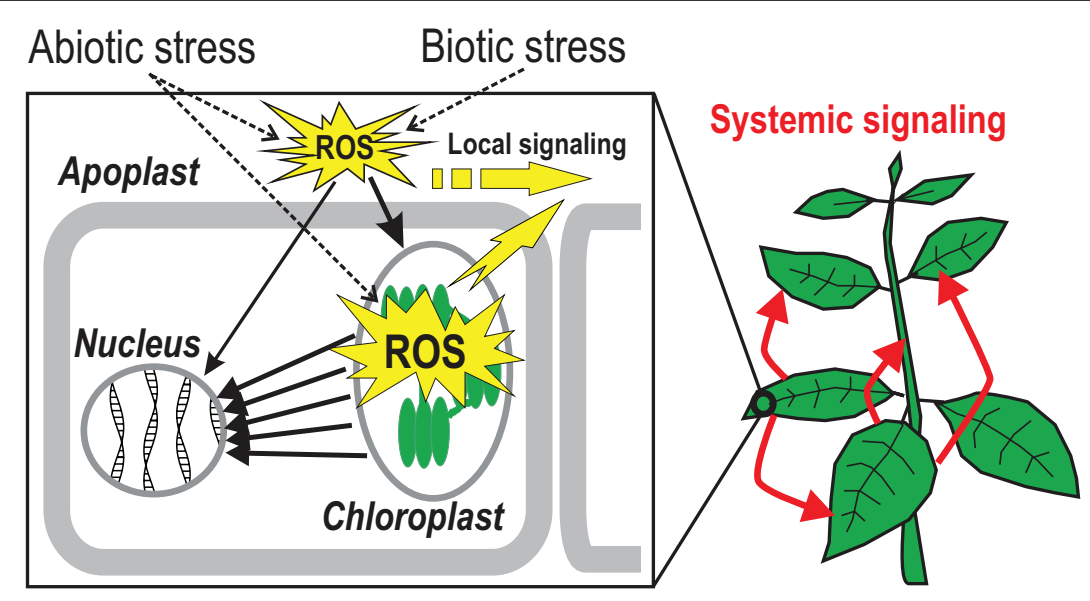

FIGURE 1 | Reactive oxygen species (ROS)-talk in plant cells. Biotic and abiotic stimuli lead to the generation of ROS in the apoplast which is subsequently communicated to the inside of the cell where the signal leads to an increase in chloroplastic ROS production. The chloroplast can further amplify the signal and transmit it to the nucleus via various cytosolic signaling networks. Apoplastic ROS signaling can also reach the nucleus through cytosolic pathways directly. Yellow arrows demonstrate intracellular transmission of apoplastic and chloroplastic ROS-induced signals where they connect neighboring cells (local signaling) or participate in long-distance ("systemic") signaling throughout the plant (red arrows).

\section{ROS IN THE APOPLAST}

Likely candidates involved in the apoplast-to-chloroplast signaling are ROS produced in the cell wall. Their accumulation in response to different abiotic and biotic stimuli during the socalled apoplastic "oxidative burst" depends on several classes of enzymes, including cell wall peroxidases (Bindschedler et al., 2006) and plasma membrane NADPH oxidases (Figure 2; Torres et al., 2002; Suzuki et al., 2011). The latter enzymes, commonly known as respiratory burst oxidase homologs (Rboh) are transmembrane flavoproteins that oxidize cytoplasmic NADPH, translocate electrons across plasma membrane and reduce extracellular ambient (triplet) oxygen to yield $\mathrm{O}_{2}^{\bullet-}$ in the cell wall. Due to its charge, this short-lived ROS is unable to passively cross the lipid bilayer and remains in the apoplast, where it is rapidly converted into another species, $\mathrm{H}_{2} \mathrm{O}_{2}$, either spontaneously or in a reaction catalyzed by the superoxide dismutase (SOD; Browning et al., 2012). The functions of plant NADPH oxidases stretch beyond stress responses and include roles in development (Sagi and Fluhr, 2006; Takeda et al., 2008), in sodium transport in the xylem sap (Jiang et al., 2012), and intriguingly also in long-distance ("systemic") ROS signaling (Miller et al., 2009). In Arabidopsis wounding, heat stress, high light, and increased salinity result in RbohD-dependent systemic spread of the oxidative burst along the rosette leaves. The signal is triggered by intracellular $\mathrm{Ca}^{2+}$ spiking at the wounding site. It is propelled by accumulation of ROS in the apoplast and by - still unidentified - symplastic signals, one of which might be ROS production in chloroplasts: results by Joo et al. (2005) suggest that chloroplastic ROS is required for intercellular ROS signaling. This ROS "wave" travels across an Arabidopsis rosette at a rate of approximately $8 \mathrm{~cm}$ per minute (Miller et al., 2009). Taken together, the currently available data suggests different roles for ROS in strictly localized signaling events but also in systemic signaling.

We have obtained a good understanding of the processes in which apoplastic ROS are involved, but how they are perceived by plant cells remains unclear. It is not known how the signal is transmitted to the cytoplasm, the chloroplasts and eventually the nucleus and what are the interactions between the different subcellular compartments. The possibility of $\mathrm{O}_{2}^{\bullet-}$ itself being the mediator of downstream signaling would require superoxidespecific extracellular receptors or anion channels in the direct vicinity to the site of $\mathrm{O}_{2}^{\bullet-}$ production (Browning et al., 2012). Anion channels have been shown to mediate superoxide import in mammalian cells (Hawkins et al., 2007) thereby linking extracellular and intracellular ROS signaling. Analogous systems in plants have so far not been identified. Unlike superoxide, the $\mathrm{H}_{2} \mathrm{O}_{2}$ molecule is relatively stable (with a half-life of $\sim 1 \mathrm{~ms}$ ) under physiological conditions and in many respects resembles a molecule of water. Its dipole moment, similar to that of $\mathrm{H}_{2} \mathrm{O}$, limits passive diffusion of $\mathrm{H}_{2} \mathrm{O}_{2}$ through biological membranes. Possible candidates for the import of apoplastic $\mathrm{H}_{2} \mathrm{O}_{2}$ are aquaporins (Figure 2), a ubiquitous family of channel proteins that has undergone an extensive expansion in vascular plants (Zardoya, 2005; Soto et al., 2012). Recent studies have identified several aquaporins as specific $\mathrm{H}_{2} \mathrm{O}_{2}$ transporters in Arabidopsis (Bienert etal., 2007; Dynowski et al., 2008; Hooijmaijers et al., 2012). However, further research is required to assess the role of $\mathrm{H}_{2} \mathrm{O}_{2}$ transport during the oxidative burst. In addition to transport across membranes, $\mathrm{O}_{2}^{\bullet-}$ and $\mathrm{H}_{2} \mathrm{O}_{2}$ may be sensed by a number of apoplastic compounds. Oxidation of extracellular pools of glutathione and ascorbic acid might play a role in transmitting the redox signal to the cytosol (Destro et al., 2011; Foyer and Noctor, 2011; Noctor et al., 2012). ROS can also be perceived by the apoplastic proteins and/or plasma membranelocalized receptors through redox modification of their cysteine residues (Figure 2). Those putative receptors or other sensory systems for extracellular ROS in plants have so far remained elusive, but for example, several classes of receptor-like protein kinases (RLKs) with cysteine-rich extracellular domains (most notably the CYSTEINE-RICH RLKs, CRKs) have been suggested to be 


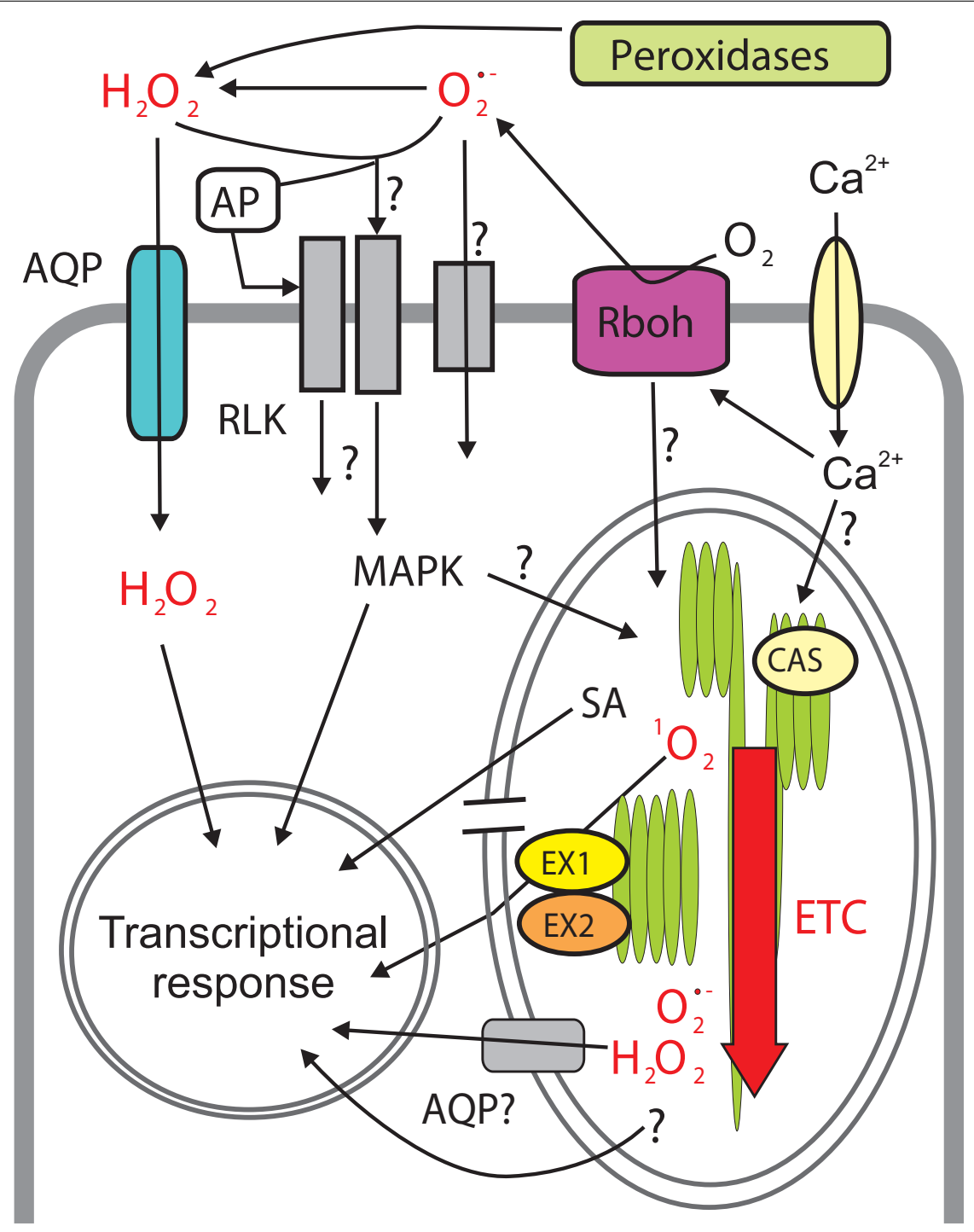

FIGURE 2 | Reactive oxygen species (ROS) signaling networks connecting apoplast, chloroplast and nucleus. Apoplastic ROS are produced by extracellular peroxidases (hydrogen peroxide; $\mathrm{H}_{2} \mathrm{O}_{2}$ ) and plasma membrane-bound NADPH oxidases, Rboh. Superoxide $\left(\mathrm{O}_{2}^{\bullet-}\right)$ is then converted to $\mathrm{H}_{2} \mathrm{O}_{2} \cdot \mathrm{H}_{2} \mathrm{O}_{2}$ (and possibly $\mathrm{O}_{2}^{\bullet-}$ ) might enter the cell through plasma membrane channels (aquaporins, AQP) and/or react with extracellular (apoplastic protein, AP) or transmembrane sensor proteins (e.g., receptor-like kinases, RLKs) ultimately resulting in changes in gene expression through intracellular signaling pathways, involving, for example, MAPKs (mitogen-activated protein kinases). Extracellular ROS production is sensed via yet unknown mechanisms in the chloroplast where ROS generation by the electron transfer chain (ETC) subsequently increases. Singlet oxygen $\left({ }^{1} \mathrm{O}_{2}\right)$ and $\mathrm{O}_{2}^{\bullet-} / \mathrm{H}_{2} \mathrm{O}_{2}$ are produced in different domains of ETC. Elevated ROS inside the chloroplast results in transcriptional reprogramming through identified (e.g., EXECUTER1/2, EX1/EX2, rupture of chloroplast envelope) and unknown components of the retrograde signaling but also through hormone signaling, e.g., increased production of the stress hormone salicylic acid (SA). Channel proteins (AQP) might also allow ROS leak from the chloroplast to the cytoplasm. Calcium $\left(\mathrm{Ca}^{2+}\right)$ is involved in the regulation of ROS production in the apoplast and the chloroplast. In the latter case it acts through the sensory protein CALCIUM-SENSING RECEPTOR (CAS) but the mechanisms are still unclear. involved in ROS perception (Shiu and Bleecker, 2003; Wrzaczek et al., 2010).

\section{FROM BEYOND TO HERE, SIGNALS FROM THE EXTRACELLULAR SPACE}

What happens in the plant cell after an extracellular oxidative burst has been triggered? A connection of apoplastic and chloroplastic ROS into common signaling networks during the plant stress response is evident in various model systems and processes (Joo et al., 2005; Vahisalu et al., 2010), although it is mechanistically still largely unexplained. The results suggest that the apoplastic ROS signal is transduced to the chloroplasts, where a secondary ROS production is initiated. This signal transmission might use cytosolic signaling components. Also, the location of chloroplasts close to the plasma membrane might facilitate direct communication between the two organelles. Thus, the chloroplast can act as 
an "amplifier," or "execute" the signal received from the apoplast (Figure 1).

One of the examples of such a role of chloroplasts is the plant immune response to pathogens that is accompanied by a bi-phasic accumulation of ROS. The first phase occurs within tens of minutes from the onset of infection. It is mostly apoplastic and is tightly linked to NADPH oxidase activity (Figure 2). The second increase in ROS production happens several hours after the pathogen attack (Lamb and Dixon, 1997; Jones and Dangl, 2006). During this stage of response the infected cells might undergo programmed cell death (PCD) leading to the collapse of the infected tissue and, in the case of biotrophic pathogens, to suppression of pathogen growth. This specialized form of pathogen-triggered PCD is a part of the hypersensitive response (HR). Different subcellular compartments including apoplast, chloroplasts, mitochondria, and peroxisomes contribute to ROS production during $\mathrm{HR}$, but a growing amount of evidence suggests a crucial role for the chloroplast in this process (Yao and Greenberg, 2006; Liu et al., 2007; Zurbriggen et al., 2009, 2010). Silencing of the chloroplast redox proteins peroxiredoxin and $\mathrm{NADPH}$-dependent thioredoxin reductase $\mathrm{C}$ that scavenge chloroplastic $\mathrm{H}_{2} \mathrm{O}_{2}$ led to spreading PCD in response to application of coronatine, a phytotoxin with structural similarity to jasmonic acid produced by several pathogenic strains of Pseudomonas (Ishiga et al., 2012). The involvement of chloroplasts in plant immunity is further supported by the observation that the pathogen resistance of plants differs between light and dark (Roden and Ingle, 2009) and by the fact that several bacterial and viral elicitors interact with chloroplast-targeted proteins or are imported into chloroplasts (Padmanabhan and Dinesh-Kumar, 2010). Thus, not only the apoplast and the cytosol, but also the chloroplasts are strategic battlefields during the defense against pathogens (Padmanabhan and Dinesh-Kumar, 2010).

Chloroplast-generated ROS are not only involved in initiating and promoting cell death during the HR, but also in the up-regulation of defense-related genes, down-regulation of photosynthesis genes and even in limiting the spread of the cell death (Straus etal., 2010). For example, a significant portion of the genes induced by artificial metabolic overproduction of $\mathrm{H}_{2} \mathrm{O}_{2}$ via expression of glyoxylate oxidase in the chloroplasts (Balazadeh et al., 2012), are also induced by chitin, a well-known elicitor of the apoplastic oxidative burst and downstream pathogen defense responses. Similarly, silencing of thylakoid ascorbate peroxidase (tAPX) led to an increase in $\mathrm{H}_{2} \mathrm{O}_{2}$ production and to activation of defense responses (Maruta et al., 2012), including the accumulation of the stress hormone salicylic acid (SA), a central mediator of plant pathogen defense. These examples underline that $\mathrm{H}_{2} \mathrm{O}_{2}$ accumulation in the chloroplast and the related retrograde signaling are involved in the activation of defense genes during responses to pathogens.

\section{CHLOROPLASTS AS THE PET PEEVE OF THE PLANT CELL}

Why does the plant cell involve the chloroplast, the major site of energy production and biosynthesis in stress responses? One explanation is that photosynthesizing chloroplasts continuously produce ROS due to numerous electron transfer reactions in the presence of oxygen (Foyer and Noctor, 2003; Asada, 2006). Hence, in the photosynthesizing plant tissues chloroplasts are able to produce the most massive pools of ROS among different subcellular compartments.

Generation of ROS in the chloroplasts depends on multiple aspects of chloroplast physiology including photosynthesis, gene expression, chlorophyll (tetrapyrrole) biosynthesis, and hormonal control (Asada, 2006; Sierla et al., 2012). For example, the production of $\mathrm{O}_{2}^{\bullet-} / \mathrm{H}_{2} \mathrm{O}_{2}$ by photosystem I (PS I) varies according to changing photosynthetic electron transfer and $\mathrm{CO}_{2}$ fixation rate. Extracellular stimuli, such as recognition of bacterial components by the plasma membrane receptors, can rapidly regulate chloroplastic functions. During plant-pathogen interactions the cues perceived in the apoplast trigger MAPK cascades (Figure 2) and result in fast down-regulation of photosynthetic genes and accumulation of $\mathrm{H}_{2} \mathrm{O}_{2}$ in chloroplasts that is necessary for initiation of HR-mediated cell death (Liu et al., 2007). Another example is the transient decrease in the ability of PS II to dissipate excessive light energy as heat via non-photochemical quenching (NPQ) at an early stage of pathogen recognition. This decrease in NPQ makes chloroplasts more predisposed to the production of ROS, which might be a priming mechanism for chloroplast ROS signaling at later stages of immune response (Göhre et al., 2012). Several chloroplastic redox hubs, including the plastoquinone as well as the glutathione pools and the thioredoxin system, provide not only dynamic local regulation of photosynthesis, but also might communicate the chloroplast redox status to the cytosol (Marty et al., 2009; Bashandy et al., 2010; Foyer and Noctor, 2011; Noctor et al., 2012; Rochaix, 2012). For example, the redox state of plastoquinone, a component of photosynthetic electron transfer chain, is monitored through the thylakoid-associated protein kinase STATE TRANSITION 7 (STN7). STN7-dependent phosphorylation of chloroplast proteins leads on the one hand to optimization of photosynthesis in response to changing light conditions ( via the reversible reallocation of light-harvesting antennae called state transitions) and on the other hand to a retrograde signal (Bonardi et al., 2005; Rochaix, 2012). Another chloroplast protein kinase, CHLOROPLAST SENSOR KINASE (CSK), couples plastoquinone redox state to the regulation of chloroplast gene expression (Puthiyaveetil et al., 2012). The soldat8 mutation in the chloroplastic RNA polymerase SIGMA SUBUNIT 6 (SIG6) gene increases the tolerance of seedlings to ${ }^{1} \mathrm{O}_{2}$ (Coll et al., 2009), which links chloroplast transcriptional control to the ROS signaling. The RNA-binding chloroplast protein GENOMES UNCOUPLED 1 (GUN1) is implicated both in chloroplast translation and tetrapyrrole biosynthesis and is somehow involved in retrograde signaling (Czarnecki et al., 2011; Woodson et al., 2012). GUN1, and one of the key components of tetrapyrrole biosynthesis, the $\mathrm{ChlH}$ subunit of magnesium chelatase, are also involved in abscisic acid signaling (Shen et al., 2006; Koussevitzky et al., 2007; Cutler et al., 2010; Shang et al., 2010). The heme, the product of a side branch of tetrapyrrole biosynthesis, exits chloroplasts to be used as a cofactor by numerous hemoproteins in the cell and to provide positive feedback on transcription of nuclear genes that encode chlorophyll-binding proteins of chloroplasts (Nott et al., 2006; Woodson et al., 2011, 2012; Czarnecki and Grimm, 2012). The disturbance of the cell affects the delicate physiological equilibrium of the chloroplasts resulting in elevated ROS production. 


\section{CHLOROPLASTIC ROS AS SIGNALS}

Plant cells have over the course of evolution learned to use chloroplastic ROS for signaling purposes. Several studies have demonstrated a central role for the highly reactive singlet oxygen $\left({ }^{1} \mathrm{O}_{2}\right)$ as a chloroplastic signal involved in the regulation of plant cell death. PS II and its light-harvesting antennae produce ${ }^{1} \mathrm{O}_{2}$ when light-excited chlorophylls adopt the rare triplet state and then reduce triplet oxygen (Krieger-Liszkay et al., 2008). Production of ${ }^{1} \mathrm{O}_{2}$ is enhanced when the light-excited electrons cannot escape PS II chlorophylls because the downstream components of electron transfer chain (mainly the plastoquinone pool) are already over-reduced, a situation typical of excessive illumination. ${ }^{1} \mathrm{O}_{2}$ readily reacts with lipids, proteins, and pigments and is rapidly quenched by water, which makes its diffusion distance from the site of production shortest among all ROS (Asada, 2006). For that reason ${ }^{1} \mathrm{O}_{2}$ is unlikely to leave the chloroplasts, but several products of ${ }^{1} \mathrm{O}_{2}$-dependent lipid or carotenoid oxidation, including oxylipins (op den Camp et al., 2003; Przybyla et al., 2008) and volatile $\beta$-cyclocitral (Ramel et al., 2012), are suspected to act as the ${ }^{1} \mathrm{O}_{2}$-dependent retrograde signal.

The Arabidopsis flu mutant (Meskauskiene et al., 2001) has been used as a genetic tool to identify ${ }^{1} \mathrm{O}_{2}$-responsive genes and to dissect signaling pathways triggered by ${ }^{1} \mathrm{O}_{2}$ production in chloroplasts. The chloroplast-localized FLU protein inhibits one of the early enzymes of tetrapyrrole biosynthesis. Flu seedlings are unable to control the biosynthetic pathway through negative feedback and accumulate the chlorophyll precursor protochlorophyllide in the dark. Being transferred to light, the seedlings bleach and die due to the massive generation of ${ }^{1} \mathrm{O}_{2}$ in their chloroplasts. This death is primarily caused by a profound reprogramming of nuclear transcription rather than by mere chemical toxicity of ${ }^{1} \mathrm{O}_{2}$ (op den Camp et al., 2003). In addition, shortly after the exposure of $\mathrm{flu}$ seedlings to light, their chloroplasts rupture releasing the soluble stroma into the cytosol - this resembles the leakage of mitochondrial proteins to the cytosol during the mitochondria-triggered PCD. Two homologous chloroplast proteins EXECUTER1 and EXECUTER2 (Figure 2) conserved in higher plants are involved in this process, although their exact role is unknown (Wagner et al., 2004; Lee et al., 2007; Kim et al., 2012). It should be noted that although ${ }^{1} \mathrm{O}_{2}$-dependent PCD is significantly exacerbated in $\mathrm{flu}$, it is not confined to the mutant but is also observed in wild-type Arabidopsis under severe light stress (Kim et al., 2012). The sensory and signaling systems involved in the transmission of the chloroplastic ${ }^{1} \mathrm{O}_{2}$-dependent signal to nucleus have not been identified, but it has been suggested that nuclear topoisomerase VI could act as an integrator of ${ }^{1} \mathrm{O}_{2}$-dependent signal in regulating nuclear gene expression (Šimková et al., 2012).

Apart from triggering PCD, the transcriptional reprogramming of $f l u$ induces many genes of stress response and leads to rapid accumulation of SA, inducing a defense pathway characteristic of plant reaction to pathogens or wounding (Ochsenbein et al., 2006; Lee et al., 2007). One of the mechanisms triggering this pathway exploits the calcium-sensing protein CAS localized to chloroplast thylakoids (Figure 2). Regulation of CAS activity is linked to the state of photosynthetic electron transfer chain. CAS has earlier been shown to be involved in high light acclimation of the green alga Chlamydomonas reinhardtii (Petroutsos et al., 2011) and it is phosphorylated by the thylakoid protein kinase STN8 (Vainonen et al., 2008), a paralog of STN7, which suggests a link between the CAS activity and the redox state of the plastoquinone pool. However, CAS is not only involved in light-dependent retrograde signaling: also various abiotic or biotic stress stimuli activate CAS through a yet unknown mechanism. This activation leads to reallocation of $\mathrm{Ca}^{2+}$ ions within the chloroplast and to accumulation of ${ }^{1} \mathrm{O}_{2}$, which, in turn, initiates defense responses through an unidentified retrograde signal (Nomura et al., 2012). Thus, CAS appears to act in the ${ }^{1} \mathrm{O}_{2}$-dependent retrograde signaling pathway discussed above.

Another source of ROS in chloroplasts is PS I. Its electrondonor side generates $\mathrm{O}_{2}^{\bullet-}$ that is scavenged by chloroplast SOD to form $\mathrm{H}_{2} \mathrm{O}_{2}$ (Asada, 2006). $\mathrm{H}_{2} \mathrm{O}_{2}$, in turn, is reduced to water by a number of enzymes including ascorbate peroxidase (APX), peroxiredoxin, and glutathione peroxidase. $\mathrm{H}_{2} \mathrm{O}_{2}$ produced in chloroplasts gives rise to retrograde signals. The signaling is not well understood and might be a combination of passive diffusion of $\mathrm{H}_{2} \mathrm{O}_{2}$ with indirect pathways including hormonal (abscisic acid) signaling (Mullineaux and Karpinski, 2002; Galvez-Valdivieso and Mullineaux, 2010). The possibility of $\mathrm{H}_{2} \mathrm{O}_{2}$ leakage from chloroplasts is supported by the fact that a knockout of cytosolic APX1 leads to hypersensitivity of the photosynthetic apparatus to light stress (Davletova et al., 2005). Diffusion of $\mathrm{H}_{2} \mathrm{O}_{2}$ from chloroplasts has also been demonstrated in vitro (Mubarakshina et al., 2010). Aquaporins in the chloroplast envelope (Figure 2) seem to be involved in this $\mathrm{H}_{2} \mathrm{O}_{2}$ leakage (Borisova et al., 2012), but how the aquaporins are regulated is unknown. In any case, $\mathrm{H}_{2} \mathrm{O}_{2}$ itself is not likely to be the retrograde signaling substance that directly affects nuclear gene expression. More probably, it is sensed by compartment-specific redox-sensitive components, which mediate the signal to the nucleus (Sierla et al., 2012). Oxidized proteins or peptides have been suggested as one of the possible downstream mediators of such $\mathrm{H}_{2} \mathrm{O}_{2}$ signaling (Wrzaczek et al., 2009; Møller and Sweetlove, 2010).

\section{THE FRUSTRATING COMPLEXITY OF ROS RESPONSES}

One of the most frequently employed tools to investigate the role of $\mathrm{O}_{2}^{\bullet-}$ in the chloroplast is the herbicide methyl viologen $(\mathrm{MV}$; also known as paraquat). $\mathrm{MV}$ accelerates the production of $\mathrm{O}_{2}^{\bullet-}$ by PS I and inhibits APX, leading to the accumulation of $\mathrm{H}_{2} \mathrm{O}_{2}$ in MV-treated plants (Mano et al., 2001). Comparison of the transcriptional responses to ${ }^{1} \mathrm{O}_{2}$ and $\mathrm{H}_{2} \mathrm{O}_{2}$ using the flu mutant and the plants treated with MV demonstrated the specific and to a large extent antagonistic effect of these two chloroplastic ROS on gene expression (op den Camp et al., 2003; Gadjev et al., 2006; Laloi et al., 2007). Interestingly, the transcriptional response to apoplastic $\mathrm{H}_{2} \mathrm{O}_{2}$ produced during oxidative burst has little similarity to the effect of either chloroplastic $\mathrm{O}_{2}^{\bullet-} / \mathrm{H}_{2} \mathrm{O}_{2}$ or chloroplastic ${ }^{1} \mathrm{O}_{2}$ (Gadjev et al., 2006; Miller et al., 2009; Petrov et al., 2012; Sierla et al., 2012). This illustrates a remarkable specificity of cellular responses to different types and subcellular sources of ROS production. This also demonstrates the complexity of ROS signaling and raises the question of the mechanisms responsible for such specificity.

Clustering results of microarray experiments involving ROS production in different subcellular compartments reveals distinct 
temporal signatures. For example, the gene expression profiles $4 \mathrm{~h}$ after elicitation with flg22 (a 22-amino acid fragment of the bacterial flagellar protein flagellin, which induces an apoplastic oxidative burst via the activation of NADPH oxidase) have similarities to the profiles induced by ozone, while $12 \mathrm{~h}$ after flg22 treatment the expression profile resembled that of chloroplastic ROS production induced by MV (Sierla et al., 2012). Ozone triggers generation of ROS in the apoplast, which leads to subsequent chloroplastic ROS production and transcriptional up-regulation of 25 (out of 44) Arabidopsis CRK genes, but the activation profile of these genes differs from that induced by high light (Wrzaczek et al., 2010). Thus, both temporal and spatial aspects appear to be involved in determining the specificity of ROS. In addition, the outcome is most likely dictated by the specific combinations of $\operatorname{ROS}\left(\mathrm{O}_{2}^{\bullet-}, \mathrm{H}_{2} \mathrm{O}_{2}\right.$, or $\left.{ }^{1} \mathrm{O}_{2}\right)$. It is unlikely that, for example, merely a change in the cytoplasmic redox state could carry the information about the subcellular source of $\mathrm{H}_{2} \mathrm{O}_{2}$. Therefore, as proposed (Møller and Sweetlove, 2010), the signal transduction would require specific and distinct sensory systems for the different ROS in diverse subcellular compartments.

The involvement of chloroplasts in plant systemic signaling has also started to emerge recently (Joo et al., 2005; Szechyñska-Hebda et al., 2010). Excessive illumination of Arabidopsis rosettes resulted in the propagation of an electric signal as measured by changes in plasma membrane potential of bundle sheath cells of leaf central veins. The signal was systemic, i.e., it also spread over the shaded leaves of the entire rosette. It correlated with transients of $\mathrm{H}_{2} \mathrm{O}_{2}$ concentration and was altered in the mutant deficient in cytosolic APX2. Besides, the signal was deregulated by the inhibitors of photosynthetic electron transfer and blocked by a $\mathrm{Ca}^{2+}$ channel inhibitor. These observations suggest that information on light conditions perceived by the chloroplast photosynthetic apparatus is communicated to the cell, most likely through ROS production, and then propagated along the plant in $\mathrm{Ca}^{2+}$-channel dependent way (Szechyñska-Hebda et al., 2010). The possible integration of this pathway with a systemic NADPH oxidase-dependent signal (Miller et al., 2009) is the subject of further research.

The high focused localization of ROS signaling events raises the issue of organelle spatial organization inside the cell. Stromules,

\section{REFERENCES}

Apel, K., and Hirt, H. (2004). Reactive oxygen species: metabolism, oxidative stress, and signal transduction. Annu. Rev. Plant Biol. 55, 373-399.

Asada, K. (2006). Production and scavenging of reactive oxygen species in chloroplasts and their functions. Plant Physiol. 141, 391-396.

Ashtamker, C., Kiss, V., Sagi, M., Davydov, O., and Fluhr, R. (2007). Diverse subcellular locations of cryptogeininduced reactive oxygen species production in tobacco Bright Yellow2 cells. Plant Physiol. 143, 18171826.

Balazadeh, S., Jaspert, N., Arif, M., Mueller-Roeber, B. and Maurino,
V. G. (2012). Expression of ROSresponsive genes and transcription factors after metabolic formation of $\mathrm{H}_{2} \mathrm{O}_{2}$ in chloroplasts. Front. Plant Sci. 3:234. doi: 10.3389/fpls. 2012.00234

Bashandy, T., Guilleminot, J., Vernoux, T., Caparros-Ruiz, D., Ljung, K., Meyer, Y., et al. (2010). Interplay between the NADP-linked thioredoxin and glutathione systems in Arabidopsis auxin signaling. Plant Cell 22, 376-391.

Bienert, G. P., Møller, A. L., Kristiansen, K. A., Schulz, A., Møller, I. M., Schjoerring, J. K., et al. (2007). Specific aquaporins facilitate the diffusion of hydrogen peroxide across membranes. J. Biol. Chem. 282, 1183-1192. the transient protrusions of organellar surfaces that are known to be induced by stress, could be one of the mediators of this focused organellar cross-talk (Leister, 2012). Besides, all organelles move and dynamically associate with each other, and the role of this movement in stress response starts to be recognized (Suzuki et al., 2012). For example, the bacterial elicitor harpin leads to HR accompanied by redistribution of mesophyll cell chloroplasts in tobacco (Boccara et al., 2007). During the last 15 years the laws of organellar movement have started to be revealed, but the consequences of dynamic physical proximity and contact between the organelles are unknown (Suetsugu et al., 2010; Sakai and Haga, 2012). Recent studies demonstrate impairment of stress reactions in the Arabidopsis mutants which are unable to move chloroplasts in response to light stimuli or to dock them to the plasma membrane (Schmidt von Braun and Schleiff, 2008; Goh et al., 2009; Oliver et al., 2009; Lehmann et al., 2011).

\section{CONCLUDING REMARKS}

Research performed over the last two decades has made it clear that ROS signaling connects events that take place in very different subcellular locations, most importantly (but not limited to) the apoplast, the chloroplast, and the nucleus. To achieve the elaborate and fine-tuned responses to biotic and abiotic stimuli that we observe on transcriptional, biochemical, and physiological level, intense and strictly controlled communication between the subcellular "crime scenes" must take place. While some components of this information exchange have been proposed, we still lack a thorough understanding on how the apoplast, the chloroplast, and the nucleus keep in touch. It will be perhaps one of the major challenges of ROS research in plants to understand ROSinduced signaling pathways between different organelles. Once we find out which components transmit information under specific conditions, we will be able to generate an integrated view of ROS signaling and its role in environmental adaptation.

\section{ACKNOWLEDGMENTS}

Research in the Plant Stress group of Professor Jaakko Kangasjärvi is supported by Biocentrum Helsinki, the Academy of Finland, the University of Helsinki, and the ERA-PG.
Bindschedler, L. V., Dewdney, J., Blee, K. A., Stone, J. M., Asai, T., Plotnikov, J., et al. (2006). Peroxidasedependent apoplastic oxidative burst in Arabidopsis required for pathogen resistance. Plant J. 47, 851-863.

Boccara, M., Schwartz, W., Guiot, E., Vidal, G., De Paepe, R., Dubois, A., et al. (2007). Early chloroplastic alterations analysed by optical coherence tomography during a harpin-induced hypersensitive response. Plant J. 50, 338-346.

Bonardi, V., Pesaresi, P., Becker, T., Schleiff, E., Wagner, R., Pfannschmidt, T., et al. (2005). Photosystem II core phosphorylation and photosynthetic acclimation require two different protein kinases. Nature 437, 1179-1182.
Borisova, M. M., Kozuleva, M. A., Rudenko, N. N., Naydov, I. A., Klenina, I. B., and Ivanov, B. N. (2012). Photosynthetic electron flow to oxygen and diffusion of hydrogen peroxide through the chloroplast envelope via aquaporins. Biochim. Biophys. Acta 1817, 1314-1321.

Browning, E. A., Chatterjee, S., and Fisher, A. B. (2012). Stop the flow: a paradigm for cell signaling mediated by reactive oxygen species in the pulmonary endothelium. Annu. Rev. Physiol. 74, 403-424.

Coll, N. S., Danon, A., Meurer, J., Cho, W. K., and Apel, K. (2009). Characterization of soldat8, a suppressor of singlet oxygen-induced cell death in Arabidopsis seedlings. Plant Cell Physiol. 50, 707-718. 
Cutler, S. R., Rodriguez, P. L., Finkelstein, R. R., and Abrams, S. R. (2010). Abscisic acid: emergence of a core signaling network. Annu. Rev. Plant Biol. 61, 651-679.

Czarnecki, O., and Grimm, B. (2012). Post-translational control of tetrapyrrole biosynthesis in plants, algae, and cyanobacteria. J. Exp. Bot. 63, 1675-1687.

Czarnecki, O., Hedtke, B., Melzer, M., Rothbart, M., Richter, A., Schröter, Y., et al. (2011). An Arabidopsis GluTR binding protein mediates spatial separation of 5-aminolevulinic acid synthesis in chloroplasts. Plant Cell 23, 4476-4491.

Davletova, S., Rizhsky, L., Liang, H., Shengqiang, Z., Oliver, D. J., Coutu, J., et al. (2005). Cytosolic ascorbate peroxidase 1 is a central component of the reactive oxygen gene network of Arabidopsis. Plant Cell 17, 268-281.

Destro, T., Prasad, D., Martignago, D., Bernet, I. L., Trentin, A. R., Renu, I. K., et al. (2011). Compensatory expression and substrate inducibility of $\gamma$-glutamyl transferase GGT2 isoform in Arabidopsis thaliana. J. Exp. Bot. 62, 805-814.

Dutilleul, C., Garmier, M., Noctor, G., Mathieu, C. D., Chétrit, P., Foyer, C. H., etal. (2003). Leaf mitochondria modulate whole cell redox homeostasis, set antioxidant capacity, and determine stress resistance throughaltered signaling and diurnal regulation. Plant Cell 15, 1212 1226.

Dynowski, M., Schaaf, G., Loque, D., Moran, O., and Ludewig, U. (2008). Plant plasma membrane water channels conduct the signalling molecule $\mathrm{H}_{2} \mathrm{O}_{2}$. Biochem. J. 414, 53-61.

Foyer, C. H., and Noctor, G. (2003). Redox sensing and signalling associated with reactive oxygen in chloroplasts, peroxisomes and mitochondria. Physiol. Plant 119, 355-364.

Foyer, C. H., and Noctor, G. (2009). Redox regulation in photosynthetic organisms: signaling, acclimation, and practical implications. Antioxid. Redox Signal. 11, 861-905.

Foyer, C. H., and Noctor, G. (2011). Ascorbate and glutathione: the heart of the redox hub. Plant Physiol. 155, $2-18$.

Gadjev, I., Vanderauwera, S., Gechev, T. S., Laloi, C., Minkov, I. N., Shulaev, V., etal. (2006). Transcriptomic footprints disclose specificity of reactive oxygen species signaling in Arabidopsis. Plant Physiol. 141, 436-445.
Galvez-Valdivieso, G., and Mullineaux, P. M. (2010). The role of reactive oxygen species in signalling from chloroplasts to the nucleus. Physiol. Plant $138,430-439$.

Geldner, N., and Robatzek, S. (2008). Plant receptors go endosomal: a moving view on signal transduction. Plant Physiol. 147, 1565-1574.

Goh, C. H., Jang, S., Jung, S., Kim, H. S., Kang, H. G., Park, Y. I., et al. (2009). Rice phot la mutation reduces plant growth by affecting photosynthetic responses to light during early seedling growth. Plant Mol. Biol. 69, 605-619.

Göhre, V., Jones, A. M., Sklenáø, J., Robatzek, S., and Weber, A. P. (2012). Molecular crosstalk between PAMPtriggered immunity and photosynthesis. Mol. Plant Microbe Interact. 25 1083-1092.

Hawkins, B. J., Madesh, M., Kirkpatrick, C. J., and Fisher, A. B. (2007). Superoxide flux in endothelial cells via the chloride channel-3 mediates intracellular signaling. Mol. Biol. Cell 18, 2002-2012.

Hooijmaijers, C., Rhee, J. Y., Kwak, K. J., Chung, G. C., Horie, T., Katsuhara, M., et al. (2012). Hydrogen peroxide permeability of plasma membrane aquaporins of Arabidopsis thaliana. J. Plant Res. 125, 147-153.

Imlay, J. A. (2003). Pathways of oxidative damage. Annu. Rev. Microbiol. 57, 395-418.

Imlay, J. A. (2008). Cellular defenses against superoxide and hydrogen peroxide. Annu. Rev. Biochem. 77, 755-776.

Ishiga, Y., Ishiga, T., Wangdi, T., Mysore, K. S., and Uppalapati, S. R. (2012). NTRC and chloroplast-generated reactive oxygen species regulate $P$ seudomonas syringae pv. tomato disease development in tomato and Arabidopsis. Mol. Plant Microbe Interact. 25, 294-306.

Jaillais, Y., and Chory, J. (2010). Unraveling the paradoxes of plant hormone signaling integration. Nat. Struct. Mol. Biol. 17, 642-645.

Jaspers, P., and Kangasjärvi, J. (2010). Reactive oxygen species in abiotic stress signaling. Physiol. Plant 138, 405-413.

Jiang, C., Belfield, E. J., Mithani, A. Visscher, A., Ragoussis, J., Mott, R., et al. (2012). ROS-mediated vascular homeostatic control of root-toshoot soil Na delivery in Arabidopsis. EMBO J. 31, 4359-4370.

Jones, J. D. G., and Dangl, J. L. (2006). The plant immune system. Nature 444, 323-329.

Joo, J. H., Wang, S., Chen, J. G., Jones, A. M., and Fedoroff, N. V. (2005).
Different signaling and cell death roles of heterotrimeric $G$ protein $\alpha$ and $\beta$ subunits in the Arabidopsis oxidative stress response to ozone. Plant Cell 17, 957-970.

Kami, C., Lorrain, S., Hornitschek, P. and Fankhauser, C. (2010). Lightregulated plant growth and development. Curr. Top. Dev. Biol. 91, 29-66.

Kangasjärvi, S., Neukermans, J., Li, S., Aro, E. M., and Noctor, G. (2012). Photosynthesis, photorespiration, and light signalling in defence responses. J. Exp. Bot. 63, 1619-1636. Kim, C., Meskauskiene, R., Zhang, S. Lee, K. P., Lakshmanan Ashok, M. Blajecka, K., et al. (2012). Chloroplasts of Arabidopsis are the source and a primary target of a plantspecific programmed cell death sig naling pathway. Plant Cell 24, 30263039.

Koussevitzky, S., Nott, A., Mockler, T. C., Hong, F., Sachetto-Martins, G. Surpin, M., et al. (2007). Signals from chloroplasts converge to regulate nuclear gene expression. Science 316, 715-719.

Krieger-Liszkay, A., Fufezan, C., and Trebst, A. (2008). Singlet oxygen production in photosystem II and related protection mechanism. Photosynth. Res. 98, 551-564.

Laloi, C., Stachowiak, M., PersKamczyc, E., Warzych, E., Murgia, I., and Apel, K. (2007). Crosstalk between singlet oxygen- and hydrogen peroxide-dependent signaling of stress responses in Arabidopsis thaliana. Proc. Natl. Acad. Sci. U.S.A. 104, 672-677.

Lamb, C., and Dixon, R. A. (1997). The oxidative burst in plant disease resistance. Annu. Rev. Plant Physiol. Plant Mol. Biol. 48, 251-275.

Lee, K. P., Kim, C., Landgraf, F., and Apel, K. (2007). EXECUTER1- and EXECUTER2-dependent transfer of stress-related signals from the plastid to the nucleus of Arabidopsis thaliana. Proc. Natl. Acad. Sci. U.S.A. 104 10270-10275.

Lehmann, P., Nöthen, J., Schmidt von Braun, S., Bohnsack, M. T., Mirus, O., and Schleiff, E. (2011). Transitions of gene expression induced by short-term blue light. Plant Biol. 13, 349-361.

Leister, D. (2012). Retrograde signaling in plants: from simple to complex scenarios. Front. Plant Sci. 3:135. doi: 10.3389/fpls.2012.00135

Liu, Y., Ren, D., Pike, S., Pallardy, S., Gassmann, W., and Zhang, S. (2007). Chloroplast-generated reactive oxygen species are involved in hypersensitive response-like cell death mediated by a mitogen-activated protein kinase cascade. Plant J. 51, 941-954.

Mano, J., Ohno, C., Domae, Y., and Asada, K. (2001). Chloroplastic ascorbate peroxidase is the primary target of methylviologeninduced photooxidative stress in spinach leaves: its relevance to monodehydroascorbate radical detected with in vivo ESR. Biochim. Biophys. Acta 1504, 275-287.

Marchi, S., Giorgi, C., Suski, J. M., Agnoletto, C., Bononi, A., Bonora, M., et al. (2012). Mitochondria-ros crosstalk in the control of cell death and aging. J. Signal Transduct. 2012, 329635.

Marty, L., Siala, W., Schwarzländer, M., Fricker, M. D., Wirtz, M., Sweetlove, L. J., et al. (2009). The NADPH-dependent thioredoxin system constitutes a functional backup for cytosolic glutathione reductase in Arabidopsis. Proc. Natl. Acad. Sci. U.S.A. 106, 9109-9114.

Maruta, T., Noshi, M., Tanouchi, A., Tamoi, M., Yabuta, Y., Yoshimura, K., et al. (2012). $\mathrm{H}_{2} \mathrm{O}_{2}$-triggered retrograde signaling from chloroplasts to nucleus plays specific role in response to stress. J. Biol. Chem. 287, 1171711729.

Mazars, C., Thuleau, P., Lamotte, O., and Bourque, S. (2010). Cross-talk between ROS and calcium in regulation of nuclear activities. Mol. Plant 3, 706-718.

Meskauskiene, R., Nater, M., Goslings, D., Kessler, F., op den Camp, R., and Apel, K. (2001). FLU: a negative regulator of chlorophyll biosynthesis in Arabidopsis thaliana. Proc. Natl. Acad. Sci. U.S.A. 98, 12826-12831.

Miller, G., Schlauch, K., Tam, R., Cortes, D., Torres, M. A., Shulaev, V., et al. (2009). The plant NADPH oxidase RBOHD mediates rapid systemic signaling in response to diverse stimuli. Sci. Signal. 2, ra45.

Mubarakshina, M. M., Ivanov, B. N., Naydov, I. A., Hillier, W., Badger, M. R., and Krieger-Liszkay, A. (2010). Production and diffusion of chloroplastic $\mathrm{H}_{2} \mathrm{O}_{2}$ and its implication to signalling. J. Exp. Bot. 61, 3577-3587.

Mullineaux, P., and Karpinski, S. (2002). Signal transduction in response to excess light: getting out of the chloroplast. Curr. Opin. Plant Biol. 5, 43-48. Murphy, M. P., Holmgren, A., Larsson, N. G., Halliwell, B., Chang, C. J., Kalyanaraman, B., et al. (2011). Unraveling the biological roles of reactive oxygen species. Cell Metab. 13, 361-366.

Møller, I. M., and Sweetlove, L. J. (2010). ROS signalling - specificity 
is required. Trends Plant Sci. 15, 370-374.

Noctor, G., Mhamdi, A., Chaouch, S., Han, Y., Neukermans, J., MarquezGarcia, B., et al. (2012). Glutathione in plants: an integrated overview. Plant Cell Environ. 35, 454-484.

Nomura, H., Komori, T., Uemura, S., Kanda, Y., Shimotani, K., Nakai, K., et al. (2012). Chloroplast-mediated activation of plant immune signalling in Arabidopsis. Nat. Commun. 3, 926.

Nott, A., Jung, H. -S., Koussevitzky, S., and Chory, J. (2006). Plastid-tonucleus retrograde signaling. Annu. Rev. Plant Biol. 57, 739-759.

Ochsenbein, C., Przybyla, D., Danon, A., Landgraf, F., Göbel, C., Imboden, A., et al. (2006). The role of EDS1 (enhanced disease susceptibility) during singlet oxygen-mediated stress responses of Arabidopsis. Plant J. 47, 445-456.

Ogilby, P. R. (2010). Singlet oxygen: there is indeed something new under the sun. Chem. Soc. Rev. 39, 31813209.

Oliver, J. P., Castro, A., Gaggero, C., Cascón, T., Schmelz, E. A., Castresana, C., et al. (2009). Pythium infection activates conserved plant defense responses in mosses. Planta 230, 569-579.

op den Camp, R. G. L., Przybyla, D., Ochsenbein, C., Laloi, C., Kim, C. H., Danon, A., et al. (2003). Rapid induction of distinct stress responses after the release of singlet oxygen in Arabidopsis. Plant Cell 15, 2320-2332.

Overmyer, K., Brosché, M., and Kangasjärvi, J. (2003). Reactive oxygen species and hormonal control of cell death. Trends Plant Sci. 8, 335-342.

Padmanabhan, M. S., and DineshKumar, S. P. (2010). All hands on deck - the role of chloroplasts, endoplasmic reticulum, and the nucleus in driving plant innate immunity. Mol. Plant Microbe Interact. 23, 1368 1380.

Petroutsos, D., Busch, A., Janssen, I., Trompelt, K., Bergner, S. V., Weinl, S., et al. (2011). The chloroplast calcium sensor CAS is required for photoacclimation in Chlamydomonas reinhardtii. Plant Cell 23, 2950-2963.

Petrov, V., Vermeirssen, V., De Clercq, I., Van Breusegem, F., Minkov, I., Vandepoele, K., et al. (2012). Identification of cis-regulatory elements specific for different types of reactive oxygen species in Arabidopsis thaliana. Gene 499, 52-60.

Przybyla, D., Göbel, C., Imboden, A., Hamberg, M., Feussner, I., and Apel, K. (2008). Enzymatic, but not non-enzymatic, ${ }^{1} \mathrm{O}_{2}$-mediated peroxidation of polyunsaturated fatty acids forms part of the EXECUTER1dependent stress response program in the flu mutant of Arabidopsis thaliana. Plant J. 54, 236-248.

Puthiyaveetil, S., Ibrahim, I. M., and Allen, J. F. (2012). Oxidationreduction signalling components in regulatory pathways of state transitions and photosystem stoichiometry adjustment in chloroplasts. Plant Cell Environ. 35, 347-359.

Ramel, F., Birtic, S., Ginies, C. Soubigou-Taconnat, L., Triantaphylidès, C., and Havaux, M. (2012). Carotenoid oxidation products are stress signals that mediate gene responses to singlet oxygen in plants. Proc. Natl. Acad. Sci. U.S.A. 109, 5535-5540.

Rochaix, J.-D. (2012). Regulation of photosynthetic electron transport. Biochim. Biophys. Acta 180, 375-383.

Roden, L. C., and Ingle, R. A. (2009) Lights, rhythms, infection: the role of light and the circadian clock in determining the outcome of plantpathogen interactions. Plant Cell 21, 2546-2552.

Sagi, M., and Fluhr, R. (2006). Production of reactive oxygen species by plant NADPH oxidases. Plant Physiol. 141, 336-340.

Sakai, T., and Haga, K. (2012). Molecular genetic analysis of phototropism in Arabidopsis. Plant Cell Physiol. 53, 1517-1534.

Schmidt von Braun, S., and Schleiff, E. (2008). The chloroplast outer membrane protein CHUP1 interacts with actin and profilin. Planta 227, 11511159.

Shang, Y., Yan, L., Liu, Z. Q., Cao, Z., Mei, C., Xin, Q., et al. (2010). The Mg-chelatase H subunit of Arabidopsis antagonizes a group of WRKY transcription repressors to relieve ABA-responsive genes of inhibition. Plant Cell 22, 1909-1935.

Shen, Y.-Y., Wang, X.-F., Wu, F.-Q. Du, S.-Y., Cao, Z., Shang, Y., et al. (2006). The Mg-chelatase $\mathrm{H}$ subunit is an abscisic acid receptor. Nature 443, 823-826.

Shiu, S. H., and Bleecker, A. B. (2003). Expansion of the receptorlike kinase/Pelle gene family and receptor-like proteins in Arabidopsis. Plant Physiol. 132, 530-543.

Sierla, M., Rahikainen, M., Salojärvi, J., Kangasjärvi, J. and Kangasjärvi, S. (2012). Apoplastic and chloroplastic redox signaling networks in plant stress responses. Antioxid. Redox Signal. doi: 10.1089/ars.2012.5016 [Epub ahead of print].

Šimková, K., Moreau, F., Pawlak, P. Vriet, C., Baruah, A., Alexandre, C., et al. (2012). Integration of stressrelated and reactive oxygen speciesmediated signals by Topoisomerase VI in Arabidopsis thaliana. Proc. Natl. Acad. Sci. U.S.A. 109, 16360-16365.

Soto, G., Alleva, K., Amodeo, G., Muschietti, J., and Ayub, N. D. (2012). New insight into the evolution of aquaporins from flowering plants and vertebrates: orthologous identification and functional transfer is possible. Gene 503, 165-176.

Straus, M. R., Rietz, S., Ver Loren van Themaat, E., Bartsch, M., and Parker, J. E. (2010). Salicylic acid antagonism of EDS1-driven cell death is important for immune and oxidative stress responses in Arabidopsis. Plant J. 62, 628-640.

Suetsugu, N., Dolja, V. V., and Wada, M. (2010). Why have chloroplasts developed a unique motility system? Plant Signal. Behav. 5, 1190-1196.

Suzuki, N., Koussevitzky, S., Mittler, R. and Miller, G. (2012). ROS and redox signalling in the response of plants to abiotic stress. Plant Cell Environ. 35 259-270.

Suzuki, N., Miller, G., Morales, J., Shulaev, V., Torres, M. A., and Mittler, R. (2011). Respiratory burst oxidases: the engines of ROS signaling. Curr. Opin. Plant Biol. 14, 691-699.

Szechyñska-Hebda, M., Kruk, J. Górecka, M., Karpiñska, B., and Karpiñski, S. (2010). Evidence for light wavelength-specific photoelectrophysiological signaling and memory of excess light episodes in Ara bidopsis. Plant Cell 22, 2201-2218.

Takeda, S., Gapper, C., Kaya, H., Bell, E., Kuchitsu, K., and Dolan, L. (2008). Local positive feedback regulation determines cell shape in roo hair cells. Science 319, 1241-1244.

Torres, M. A., Dangl, J. L., and Jones, J. D. G. (2002). Arabidopsis gp91 9 phox homologues AtrbohD and AtrbohF are required for accumulation of reactive oxygen intermediates in the plant defense response. Proc. Natl. Acad. Sci. U.S.A. 99, 517-522.

Vahisalu, T., Puzõrjova, I., Brosché, M., Valk, E., Lepiku, M., Moldau, H., et al. (2010). Ozone-triggered rapid stomatal response involves the production of reactive oxygen species, and is controlled by SLAC1 and OST1. Plant J. 62, 442-453

Vainonen, J. P., Sakuragi, Y., Stael, S., Tikkanen, M., Allahverdiyeva, Y., Paakkarinen, V., et al. (2008). Light regulation of $\mathrm{CaS}$, a novel phosphoprotein in the thylakoid membrane of Arabidopsis thaliana. FEBS J. 275, 1767-1777.

Vanstraelen, M., and Benková, E. (2012). Hormonal interactions in the regulation of plant development. Annu. Rev. Cell Dev. Biol. 28, 463487.

Wagner, D., Przybyla, D., op den Camp, R., Kim, C., Landgraf, F., Lee, K. P., et al. (2004). The genetic basis of singlet oxygen-induced stress responses of Arabidopsis thaliana. Science 306, 1183-1185.

Woodson, J. D., Perez-Ruiz, J. M., and Chory, J. (2011). Heme synthesis by plastid ferrochelatase I regulates nuclear gene expression in plants. Curr. Biol. 21, 897-903.

Woodson, J. D., Perez-Ruiz, J. M., Schmitz, R. J., Ecker, J. R. and Chory, J. (2012). Sigma factor mediated plastid retrograde signals control nuclear gene expression. Plant J. doi: 10.1111/tpj.12011 [Epub ahead of print]

Wrzaczek, M., Brosché, M., Kollist, H., and Kangasjärvi, J. (2009). Arabidopsis GRI is involved in the regulation of cell death induced by extracellular ROS. Proc. Natl. Acad. Sci. U.S.A. 106, 5412-5417.

Wrzaczek, M., Brosché, M., Salojärvi, J., Kangasjärvi, S., Idänheimo, N., Mersmann, S., et al. (2010). Transcriptional regulation of the CRK/DUF26 group of Receptorlike protein kinases by ozone and plant hormones in Arabidopsis. BMC Plant Biol. 10:95. doi: 10.1186/14712229-10-95.

Yao, N., and Greenberg, J. T. (2006). Arabidopsis ACCELERATED CELL DEATH2 modulates programmed cell death. Plant Cell 18, 397-411.

Zardoya, R. (2005). Phylogeny and evolution of the major intrinsic protein family. Biol. Cell 97, 397-414.

Zurbriggen, M. D., Carrillo, N., and Hajirezaei, M. R. (2010). ROS signaling in the hypersensitive response: when, where and what for? Plant Signal. Behav. 5, 393-396.

Zurbriggen, M. D., Carrillo, N., Tognetti, V. B., Melzer, M., Peisker, M., Hause, B., etal. (2009). Chloroplast-generated reactive oxygen species play a major role in localized cell death during the nonhost interaction between tobacco and Xanthomonas campestris pv. vesicatoria. Plant J. 60, 962-973.

Conflict of Interest Statement: The authors declare that the research was conducted in the absence of any commercial or financial relationships that could be construed as a potential conflict of interest.

Received: 19 October 2012; accepted: 07 December 2012; published online: 27 December 2012. 
Citation: Shapiguzov A, Vainonen $J P$, Wrzaczek $M$ and Kangasjärvi J (2012) ROS-talk - how the apoplast, the chloroplast, and the nucleus get the message through. Front. Plant
Sci. 3:292. doi: 10.3389/fpls.2012. 00292

This article was submitted to Frontiers in Plant Physiology, a specialty of Frontiers in Plant Science.
Copyright (c) 2012 Shapiguzov, Vainonen, Wrzaczek and Kangasjärvi. This is an open-access article distributed under the terms of the Creative Commons Attribution License, which permits use, distribution and reproduction in other forums, provided the original authors and source are credited and subject to any copyright notices concerning any thirdparty graphics etc. 